\title{
Resistência à corrosão de pós metálicos em concretos refratários contendo elevado teor de carbono
}

\section{(Corrosion resistance of metal powders in high-carbon containing castables)}

\author{
V. G. Domiciano, J. R. Garcia, V. C. Pandolfelli \\ Departamento de Engenharia de Materiais \\ Universidade Federal de S. Carlos - UFSCar \\ Rod. Washington Luiz, km 235, S. Carlos, SP 13565-905 \\ vitordomiciano@yahoo.com.br,vicpando@power.ufscar.br
}

\begin{abstract}
Resumo
Os benefícios proporcionados pela adição de carbono em concretos refratários têm ampliado a utilização destes materiais em aplicações siderúrgicas. Contudo, um dos problemas que ainda limita o emprego de concretos refratários contendo elevado teor de carbono é a corrosão de pós metálicos comumente empregados para conter a oxidação do carbono a altas temperaturas. Estudos preliminares mostraram que a corrosão das partículas metálicas é diretamente afetada pelas condições alcalinas promovidas pela presença de cimento. Diante disso, o objetivo deste trabalho foi avaliar o efeito da temperatura e a influência de diferentes agentes ligantes sobre a resistência à corrosão de pós metálicos (Al e Si) em água e em concretos refratários contendo elevado teor de carbono. Para isso, foi empregada uma técnica capaz de detectar a liberação de gás $\mathrm{H}_{2}$ como produto da reação de corrosão dos metais. Os resultados obtidos revelaram a possibilidade de aplicação dos pós metálicos em concreto refratário através da escolha de um ligante apropriado.
\end{abstract}

Palavras-chave: concreto refratário, carbono, antioxidantes, corrosão.

Abstract

The benefits promoted by carbon addition in refractory castables have led to an increase in the use of such materials in the steel making industry. Nevertheless, one of the problems that still hinder the use of high-carbon-containing castables is the corrosion of metal powders commonly used to prevent carbon oxidation at high temperatures. Preliminary studies have pointed out that the metal powders corrosion within the castables is affected by the aggressive alkaline conditions promoted by cement hydration. The present work aimed to evaluate the effect of temperature as well as the influence of different binders on the corrosion resistance of Al and Si powders in water and in high-carbon containing castables. A technique able to detect the $\mathrm{H}_{2}$-gas release was used to identify the metal powders corrosion. The results revealed the possibility of applying Al or Si powders in these systems through the selection of a suitable castable binder.

Keywords: refractory castables, carbon, antioxidants, corrosion.

\section{INTRODUÇÃO}

Atualmente, uma das grandes vertentes associadas ao desenvolvimento de refratários de alto desempenho está relacionada à produção de concretos refratários contendo elevado teor de carbono [1-2]. Estes materiais têm sido alvo de pesquisa e desenvolvimento uma vez que podem conciliar no mesmo produto as vantagens oferecidas pelos concretos (rapidez e facilidade de instalação, liberdade de formas, etc.) e a presença de carbono (grafite ou coque), que é adicionado com o objetivo de aumentar a resistência ao ataque por escória e metal fundido. No entanto, o desenvolvimento desses materiais tem sido dificultado pela grande susceptibilidade à oxidação das partículas de carbono a temperaturas superiores a $600{ }^{\circ} \mathrm{C}$. Com a oxidação do carbono, os concretos apresentam um aumento expressivo de porosidade o que promove uma redução da resistência mecânica como também da resistência à penetração de escória e metal fundido.

Uma das alternativas exploradas na tentativa de controlar a oxidação do carbono em refratários é o emprego de pós metálicos (Al, Mg, Si ou ligas metálicas), que reagem preferencialmente ao ou com o carbono, diminuindo sua taxa de oxidação [1-3]. Embora estes materiais apresentem 
um bom desempenho em tijolos contendo carbono, sua utilização em concretos refratários é limitada pela forte tendência à corrosão dos pós metálicos [1-6]. Quando adicionados aos concretos, os pós metálicos reagem com a água produzindo uma variedade de compostos (óxidos e hidróxidos metálicos) e gás hidrogênio $\left(\mathrm{H}_{2}\right)$. Assim, os pós metálicos perdem sua eficiência como antioxidantes do carbono. Além disso, a geração de grandes quantidades de $\mathrm{H}_{2}$ oferece um considerável risco de explosão [3-5].

Técnicas de recobrimento têm sido propostas na literatura como forma de inibir a corrosão dos pós metálicos em água $[3,5]$. Entretanto, quando pós recobertos foram adicionados ao concreto refratário o mesmo desempenho não foi observado. Tal comportamento foi relacionado às condições alcalinas promovidas pela presença de cimento que seriam responsáveis pela dissolução dos recobrimentos [3].

Diante destas informações, o objetivo deste trabalho foi avaliar o efeito da temperatura e a influência de diferentes agentes ligantes sobre a resistência à corrosão de pós de $\mathrm{Al}$ e Si em água e concreto refratário contendo elevado teor de carbono.

\section{MATERIAIS E MÉTODOS}

Neste trabalho foram empregados o pó de alumínio 101 (Alcoa, Brasil) e pó de silício Silgrain (Elkem Refractories, Noruega), ambos com tamanho médio de partículas inferior a $75 \mu \mathrm{m}$. A tendência à hidratação dos pós metálicos foi avaliada em ensaios em água a diferentes temperaturas (30, 50 e $70{ }^{\circ} \mathrm{C}$ ) e em concreto refratário a $50{ }^{\circ} \mathrm{C}$. O concreto empregado trata-se de uma composição UBTC (Ultra-baixoteor de cimento) no sistema $\mathrm{Al}_{2} \mathrm{O}_{3}-\mathrm{SiC}-\mathrm{SiO}_{2}-\mathrm{C}$ (Tabela I), elaborada segundo o modelo de distribuição de partículas de Andreasen com coeficiente q igual a 0,21. Foram utilizados polimetacrilato de sódio (Vanderbilt - teor: $0,97 \mathrm{mg} / \mathrm{m}^{2}$ ) como dispersante e um surfactante não-iônico (HLB 8 -

Tabela I - Composição de concreto refratário UBTC $\left(\mathrm{Al}_{2} \mathrm{O}_{3}-\mathrm{SiC}-\mathrm{SiO}_{2}-\mathrm{C}\right)$.

[Table I - ULCC refractory castable composition $\left(\mathrm{Al}_{2} \mathrm{O}_{3}-\mathrm{SiC}-\mathrm{SiO}_{2}-\mathrm{C}\right)$.]

\begin{tabular}{ccc}
\hline & Matérias-primas & \%-peso \\
\hline Agregados & Alumina Eletrofundida Branca & \\
& (EK8R malha 5/16 - 200) • & 53,5 \\
& SiC (EC6R, malha 6 - 200) - & 17,5 \\
Matriz & Alumina Calcinada (A-3000 FL) & 11,0 \\
& Cimento (CA-270) & 3,0 \\
& Microssílica (971-D) - & 5,0 \\
& Coque (Unicarbo 50) & 10,0 \\
& Pó Metálico & 0,3 \\
& Água Destilada & 6,5 \\
\hline
\end{tabular}

- Alcoa (Brasil); Almatis (EUA);- Elkem Refractories (Noruega); Unimetal (Brasil) teor: $4 \mathrm{mg} / \mathrm{m}^{2}$ ) para promover a molhabilidade e dispersão das partículas de carbono no concreto [2]. O pó metálico foi incorporado à composição a seco, antes da adição de água ao concreto. Nos ensaios em água foi mantida a relação pó metálico/ $\mathrm{H}_{2} \mathrm{O}$ empregada no concreto.

Os concretos refratários ( $\sim 500 \mathrm{~g})$ bem como as suspensões aquosas (26 g água destilada $+1,2$ g pó metálico) foram colocadas em um recipiente plástico dentro de um reator de aço inox com sistema de vedação adequado para evitar o vazamento de gás. Este reator foi imerso em um banho térmico à temperatura constante, sendo conectado a um transdutor a partir do qual foram coletadas as medidas de pressão ao longo do experimento [4]. A técnica utilizada se baseia na evolução de gás hidrogênio como forma de identificar a corrosão ou hidratação dos pós metálicos. Portanto, a elevação dos níveis de pressão dentro do reator foi atribuída à liberação de gás $\mathrm{H}_{2}$ decorrente da reação do pó metálico com a água.

Três outros ligantes foram testados em concreto refratário como alternativa ao cimento de aluminato de cálcio (CAC, CA270, Almatis-EUA): alumina hidratável (AH, Alphabond 300, Almatis-EUA), alumina coloidal (AC, Wesol A, concentração de sólidos: 20,0\%-p, $\mathrm{pH}\left(25{ }^{\circ} \mathrm{C}\right)=4,0$, Wesbond Co.-EUA) e sílica coloidal (SC, Nalco 00BLZ021, concentração de sólidos: 40,0\%-p, $\mathrm{pH}\left(25{ }^{\circ} \mathrm{C}\right)=10,1$, Nalco Co.-EUA). Nestes sistemas, os teores de AH, AC e SC empregados foram 3,0\%p, 8,1\%-p e 13,0\%-p, respectivamente. No caso dos concretos preparados com suspensões coloidais (AC ou SC), o teor de ligante empregado já continha a quantidade de água (6,5\%-p) necessária para promover fluidez ao concreto.

\section{RESULTADOS E DISCUSSÃO}

Os testes de hidratação realizados em água a diferentes temperaturas revelaram uma grande diferença na resistência à corrosão entre os dois pós metálicos (Fig. 1). Enquanto o aumento de temperatura intensificou e também acelerou a reação entre o pó de $\mathrm{Al}$ e a água, nenhuma evidência da corrosão do pó de Si foi detectada. Estes resultados sugerem que o silício possui uma maior resistência à corrosão em água ( $\mathrm{pH}$ 7) quando comparado ao alumínio. A passivação do Si é prevista pelo diagrama de Pourbaix [7], o qual indica que, sob uma ampla faixa de $\mathrm{pH}(0-10)$, o silício metálico é protegido por uma camada de $\mathrm{SiO}_{2}$ formada sobre a superfície do metal como resultado de uma ligeira reação com a água. De acordo com Pourbaix, o Si pode ser atacado quando exposto a condições alcalinas $(\mathrm{pH}>10)$ nas quais a camada protetora de $\mathrm{SiO}_{2}$ se dissolve deixando o metal desprotegido. No caso do Al, o diagrama de Pourbaix prevê a corrosão do metal tanto em $\mathrm{pH}$ ácido quanto básico [7]. A passivação do Al é verificada a partir da formação de uma camada de hidróxido de alumínio $\left(\mathrm{Al}(\mathrm{OH})_{3}\right)$ sobre a superfície do metal, a qual é estável apenas em uma estreita faixa de pH (4-6 quando recoberto por boehmita ou 4-8 quando protegido por hidrargillita) [7]. 


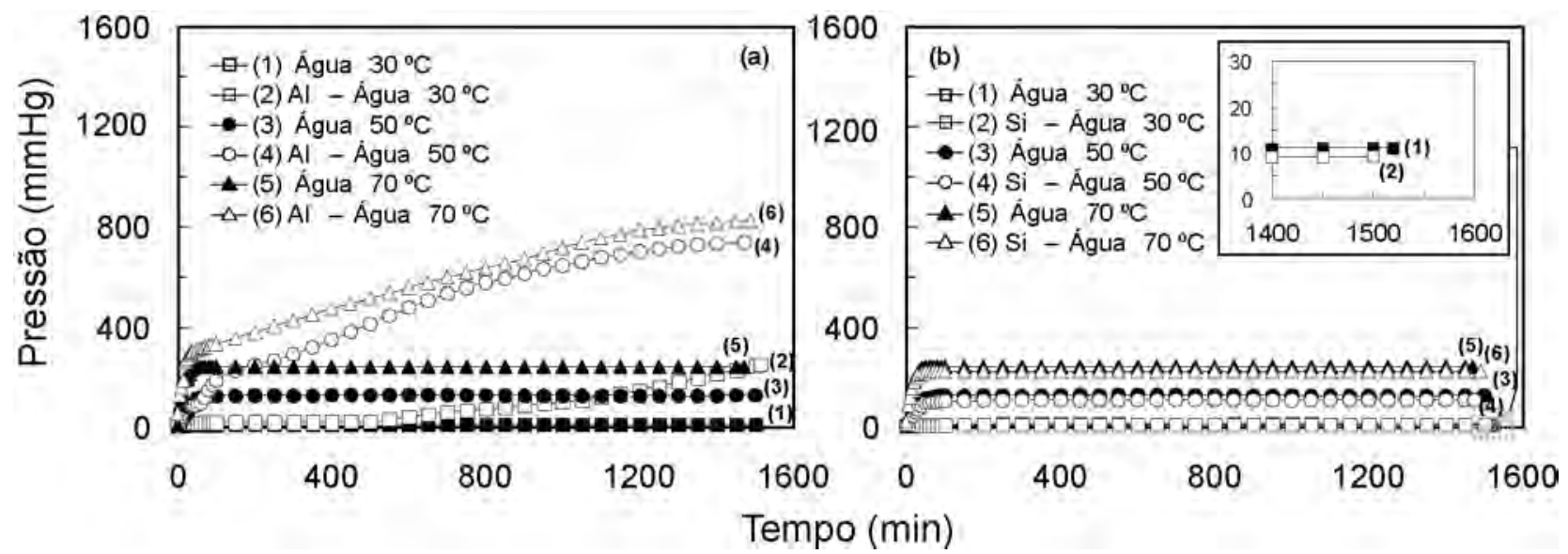

Figura 1: Resistência à corrosão do (a) pó de $\mathrm{Al}$ e (b) pó de $\mathrm{Si}$ em água a diferentes temperaturas $\left(30,50\right.$ e $\left.70^{\circ} \mathrm{C}\right)$.

[Figure 1: Corrosion resistance of (a) Al and (b)Si powders in water at different temperatures (30, 50 and $\left.70^{\circ} \mathrm{C}\right)$.]

Os testes com o pó de Al revelaram que o aumento da temperatura reduziu o tempo necessário para o início da reação além de intensificar a corrosão do metal. As diferenças observadas nos perfis de aumento de pressão foram relacionadas a mudanças químicas e físicas que a camada passivadora sofre ao longo do teste de hidratação. Neste sentido, Pourbaix et al. estabeleceram que a passivação do $\mathrm{Al}$ em água é desenvolvida por meio da geração de uma camada passivadora instável de $\mathrm{Al}(\mathrm{OH})_{3}$ amorfo [7]. Para longos tempos de exposição à água e/ou para altas temperaturas $\left(\mathrm{T}>40{ }^{\circ} \mathrm{C}\right)$, esta camada instável se cristaliza formando boehmita que, então, pode se converter em bayerita, aumentando a estabilidade química da camada passivadora, o que leva a um aumento da proteção contra corrosão [7].

De maneira semelhante, Hart [8] demonstrou que a formação da camada passivadora sobre a superfície do $\mathrm{Al}$ depende da temperatura. A temperaturas entre 20 e $60{ }^{\circ} \mathrm{C}$, o processo de corrosão ocorre em três estágios. $\mathrm{O}$ primeiro corresponde ao aumento da espessura do filme de $\mathrm{Al}(\mathrm{OH})_{3}$ amorfo. O segundo estágio está associado à geração de boehmita cristalina e o último corresponde à transformação em bayerita. Hart também relata que o aumento da temperatura (na faixa entre $20-60{ }^{\circ} \mathrm{C}$ ) é responsável por acelerar a formação dos filmes de boehmita e bayerita [8].

Estas informações podem ser usadas para compreender os resultados da Fig. 1a. Os perfis de aumento de pressão demonstram que a $50{ }^{\circ} \mathrm{C}$ ou $70{ }^{\circ} \mathrm{C}$ a reação de corrosão tem início em tempos mais curtos e ocorre com maior intensidade. Este comportamento concorda com o fato de que o aumento da temperatura eleva a solubilidade da camada de $\mathrm{Al}(\mathrm{OH})_{3}$ e acelera a cinética da reação de corrosão. Apesar da grande reatividade do $\mathrm{Al}$ em água a $70{ }^{\circ} \mathrm{C}$, a pressão gerada pela liberação de gás $\mathrm{H}_{2}$ atinge um patamar de pressão. De acordo com Pourbaix e Hart [7, 8], este comportamento pode ser atribuído à rápida cristalização da camada amorfa de $\mathrm{Al}(\mathrm{OH})_{3}$ nestas temperaturas, o que promove a passivação do metal.
Um detalhe interessante dos perfis de aumento de pressão envolvendo a corrosão do pó de $\mathrm{Al}$ a $50{ }^{\circ} \mathrm{C}$, é a semelhança entre a curva obtida e aquela de Massa vs. Tempo do trabalho de Hart [8] para placas de $\mathrm{Al}$ imersas em água a $60^{\circ} \mathrm{C}$. Este é um forte indicativo que o processo de corrosão do pó de $\mathrm{Al}$ ocorre nos três estágios descritos acima.

Testes adicionais foram realizados com os pós metálicos em água, medindo-se a variação de $\mathrm{pH}$ das suspensões aquosas ao longo do tempo de ensaio (Fig. 2). Quando o pó de $\mathrm{Al}$ foi adicionado à água a $50^{\circ} \mathrm{C}$, observou-se um aumento significativo do $\mathrm{pH}$ da suspensão até um valor constante de 9,4. Esta elevação do pH está associada ao primeiro estágio do processo de corrosão do $\mathrm{Al}$, no qual ocorre o aumento da espessura do filme de $\mathrm{Al}(\mathrm{OH})_{3}$ amorfo. Durante este processo, o filme protetor pode se dissociar em íons $\mathrm{Al}^{3+} \mathrm{e}$ $\mathrm{OH}^{-}$promovendo a elevação do $\mathrm{pH}$ verificada. É interessante notar que, de acordo com Pourbaix [7], em condições alcalinas ( $\mathrm{pH}>9,0)$ a camada de $\mathrm{Al}(\mathrm{OH})_{3}$ é instável podendo ser continuamente dissolvida deixando a superfície do metal desprotegida. No entanto, como mostrado por Hart, sob tais condições o filme amorfo de $\mathrm{Al}(\mathrm{OH})_{3}$ pode se cristalizar em boehmita e bayerita. Esta cristalização é responsável por: (1) reduzir a concentração de íons $\mathrm{OH}^{-}$em solução, o que detém o aumento do $\mathrm{pH}$ e (2) melhorar a resistência à corrosão do metal diminuindo a velocidade da reação de hidratação até que a passivação seja obtida por meio do aumento da espessura da camada protetora.

No caso do pó de Si, as medidas realizadas revelaram um pequeno decréscimo no $\mathrm{pH}$ da suspensão, alcançando um valor constante de $\sim$ 6,2. Como mencionado anteriormente, nesta faixa de $\mathrm{pH}$ (6-7), o Si seria protegido por uma camada estável de $\mathrm{SiO}_{2}$ [7]. A interação entre a camada de $\mathrm{SiO}_{2}$ e meio aquoso dá origem a um complexo equilíbrio em solução, gerando um grande número de produtos de corrosão (ácidos silícicos, por exemplo) que ao se dissociarem provocam a diminuição no $\mathrm{pH}$ do meio $[7,9]$. 


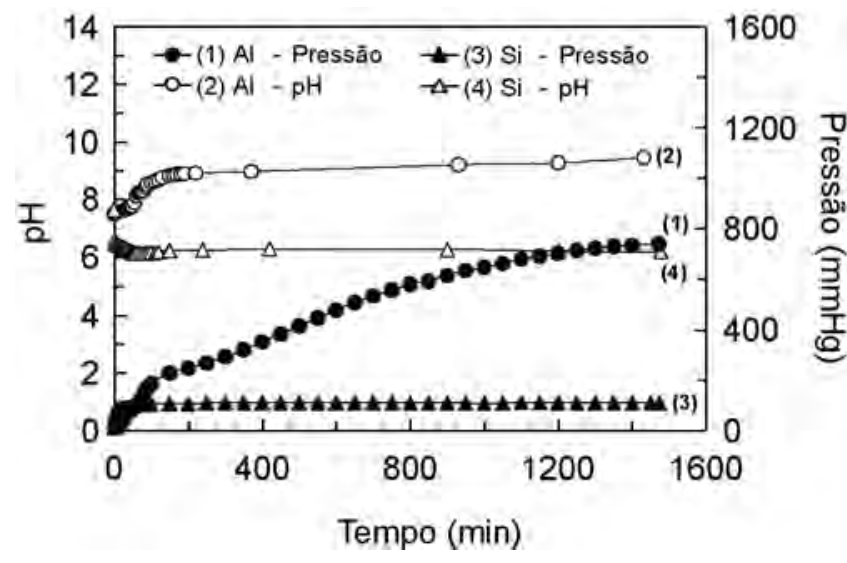

Figura 2: Variação de $\mathrm{pH}$ verificada nas suspensões aquosas contendo pó metálico a $50^{\circ} \mathrm{C}$ ao longo dos testes de hidratação. [Figure 2: pH measurements carried out in the metal powder aqueous suspension along with the hydration tests $\left.\left(50^{\circ} \mathrm{C}\right).\right]$

Os resultados discutidos acima indicam que as condições de $\mathrm{pH}$ do meio têm uma grande influência sobre a resistência à corrosão dos pós de $\mathrm{Al}$ e $\mathrm{Si}$. Por esta razão, um fator importante a ser considerado na adição de pós metálicos como antioxidantes em concretos refratários contendo carbono é o efeito das condições alcalinas promovidas pelos ligantes (por exemplo cimento) comumente empregados para conferir resistência mecânica a verde aos concretos. Para investigar a influência do $\mathrm{pH}$ do concreto sobre a resistência à corrosão das partículas metálicas, testes de hidratação foram realizados com concretos preparados com diferentes ligantes, os quais pudessem promover condições distintas de $\mathrm{pH}$ (Tabela II).

Os testes realizados revelaram uma intensa liberação de gás $\mathrm{H}_{2}$ dos concretos contendo pó de $\mathrm{Al}$ preparados com $\mathrm{CAC}$ ou $\mathrm{AH}$ (Fig. 3a). Considerando as condições de $\mathrm{pH}$ desenvolvidas pelos concretos (Tabela II) e a estabilidade da camada passivadora em meios alcalinos ( $\mathrm{pH}>9$ ), uma considerável reação entre o pó de Al e o meio aquoso já era esperada.

Apesar destes resultados previsíveis, outros testes revelaram três situações particulares.

1) Concreto sem ligante (Fig. 3a): Embora a condição de $\mathrm{pH}$ desenvolvida por este concreto $(\mathrm{pH}=8,8)$ devesse favorecer a corrosão do pó de $\mathrm{Al}$, apenas um ligeiro aumento na pressão foi observado. Em uma primeira análise, este resultado sugere que as partículas metálicas tenham sido passivadas durante o teste de hidratação. No entanto, esta não parece ser a melhor explicação para o comportamento, uma vez que resultados mostrados a seguir confirmam a corrosão do $\mathrm{Al}$ em concretos sem ligante.

2) Concreto preparado com AC: Embora a passivação do Al fosse esperada em condições levemente ácidas ( $\mathrm{pH}=5,7)$, um pequeno aumento nos níveis de pressão foi observado. Neste caso, é importante ressaltar que a passivação do $\mathrm{Al}$ prevista por Pourbaix [7], nas faixas de pH entre 4-6 ou 4-8, considera a presença de uma camada protetora de boehmita ou bayerita. Entretanto, a camada de $\mathrm{Al}(\mathrm{OH})_{3}$ inicialmente formada é amorfa, podendo ser dissolvida nas condições de pH desenvolvida pelo concreto, o que deixaria desprotegida a superfície do pó metálico. Dessa forma, a corrosão do Al aconteceria até o momento em que a passivação fosse obtida pela cristalização do filme amorfo, o que é provavelmente ilustrado pelos valores constantes de pressão alcançados após 500 min de ensaio.

3) Concreto preparado com SC: Embora o concreto tenha atingido um valor de $\mathrm{pH}$ semelhante àquele obtido pelo concreto preparado com $\mathrm{AH}$ (Tabela II), nenhuma evidência da corrosão do pó de Al foi verificada mesmo após 24 h (1440 min) de ensaio.

Os testes realizados com pó de Si mostraram que na ausência de ligante ou na presença de AH ou AC, nenhuma evidência da reação de corrosão foi observada (Fig. 3b). Como previsto pelo diagrama de Pourbaix, as condições de pH desenvolvidas por estes concretos (Tabela II) favorecem a passivação do Si.

Comportamentos inesperados foram observados nos concretos preparados com CAC e SC. De acordo com o diagrama de Pourbaix, uma intensa liberação de gás $\mathrm{H}_{2}$ deveria ser verificada nos concretos preparados com CAC em função do elevado $\mathrm{pH}$ desenvolvido $(\mathrm{pH}=12,4)$. Entretanto, nenhum aumento de pressão foi observado (Fig. 3b). A mesma situação foi constatada no teste realizado com o concreto preparado com SC. Embora o concreto tenha atingido um valor de $\mathrm{pH}$ semelhante ao verificado com o concreto preparado com AH (Tabela II), uma pequena elevação nos níveis de pressão foi detectada ao final do teste, indicando uma ligeira reação do Si com o meio aquoso.

Diante destes resultados, é importante lembrar que os experimentos realizados por Pourbaix retratam o tipo

Tabela II - Medidas de pH realizadas nos concretos refratários preparados com e sem pó metálico utilizando diferentes tipos de ligantes.

[Table II - pH measurements performed in the refractory castables produced with or without metal powder addition using different sort of binders.]

\begin{tabular}{cccc}
\hline Ligantes & $\begin{array}{c}\text { Concretos } \\
\text { sem pó } \\
\text { metálico }\end{array}$ & $\begin{array}{c}\text { Concretos } \\
\text { pó de Al }\end{array}$ & $\begin{array}{c}\text { Concretos } \\
\text { pó de Si }\end{array}$ \\
\hline Sem Ligante & 8,8 & 8,8 & 8,7 \\
AC & 5,7 & 5,7 & 5,7 \\
SC & 9,4 & 9,4 & 9,5 \\
AH & 9,2 & 9,3 & 9,2 \\
CAC & 12,4 & 12,5 & 12,5 \\
\hline
\end{tabular}

Medidas de pH realizadas após a etapa de mistura a úmido dos concretos. Os valores apresentados nesta tabela representam o pH atingido após estabilização. 


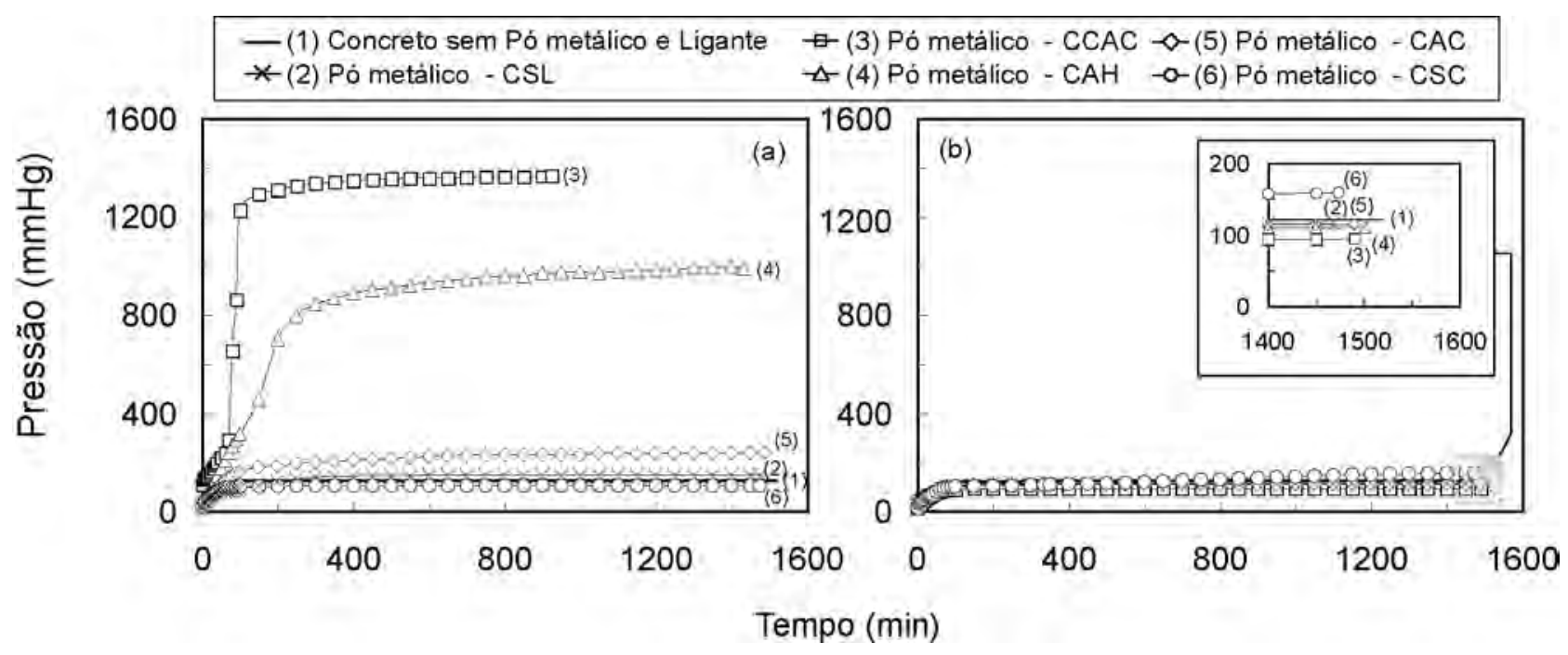

Figura 3: Resistência à corrosão do (a) pó de $\mathrm{Al}$ e (b) pó de $\mathrm{Si}$ em concretos refratários preparados sem ou com diferentes ligantes a $50^{\circ}$ C. [Concreto Sem Ligante (CSL); com Cimento de Aluminato de Cálcio (CCAC); Alumina Hidratável (CAH); Alumina Coloidal (CAC); Sílica Coloidal (CSC)].

[Figure 3: Corrosion resistance of (a)Al powder and (b)Si powder in refractory castables produced without binder addition or using different sort of binders $\left(50^{\circ} \mathrm{C}\right)$. [Binder-free castable (CSL); Calcium Aluminate Cement (CCAC); Hydratable Alumina (CAH); Colloidal Alumina (CAC); Colloidal Silica (CSC).]

de interação que acontece entre metais e o meio aquoso em condições particulares [7]. Como se pôde observar, as condições de $\mathrm{pH}$ exercem um efeito pronunciado sobre a corrosão dos metais (Fig. 3). No entanto, esta não parece ser a única variável capaz de interferir no mecanismo de corrosão ou passivação do $\mathrm{Al}$ e Si em sistemas que apresentam uma grande complexidade química, tal como um concreto refratário. Como o próprio Pourbaix menciona, os diagramas são válidos apenas para representar os fenômenos de corrosão e passivação de metais em meios livres de substâncias com as quais possam reagir formando complexos solúveis, ou ainda, sais insolúveis [7].

Diante destas informações, é possível que um outro mecanismo de passivação possa estar atuando sobre o pó de Al quando adicionado ao concreto preparado com SC, como também, sobre o pó de Si quando em concreto preparado com CAC, AH ou AC (Fig. 3). Para explicar estes comportamentos é importante compreender como a presença de $\mathrm{Al}$ pode influenciar a corrosão ou passivação do Si e vice-versa. A literatura científica relata que a solubilidade da sílica é afetada pela presença de íons polivalentes [9]. Deste modo, uma pequena quantidade de íons $\mathrm{Al}^{3+}$ é capaz de reduzir tanto a velocidade de dissolução quanto a solubilidade da sílica no equilíbrio através de adsorção química dos íons de alumínio sobre a superfície de sílica. Da mesma forma, a adição de sílica a uma suspensão de alumina reduz a solubilidade desta [9]. Este tipo de interação é um indicativo de que o novo mecanismo de passivação sugerido acima estaria associado à formação de uma camada de aluminosilicato na superfície dos pós metálicos. Para que seja verificada a formação de um recobrimento de aluminosilicato, é necessário que íons de Al e Si estejam presentes [9] em um meio cujas condições de $\mathrm{pH}$ sejam superiores a 4 [10]. Além disso, o equilíbrio mineral e o pH da solução são responsáveis por regular a concentração e o tipo das espécies iônicas geradas [9], o que pode influenciar no tipo de aluminosilicato a ser formado. Por exemplo, uma solução aquosa contendo $\sim 10^{-7} \mathrm{~mol} / \mathrm{L}$ de Al e $\sim 10^{-4} \mathrm{~mol} / \mathrm{L}$ de $\mathrm{Si}$ (na forma de $\mathrm{H}_{4} \mathrm{SiO}_{4}$ ) é considerada supersaturada em relação ao mineral caulinita [11]. Nestas condições, a precipitação de caulinita é termodinamicamente favorecida.

Portanto, as condições favoráveis à formação de aluminosilicatos seriam obtidas tanto em sistemas em que o pó de $\mathrm{Al}$ é empregado como antioxidante e o ligante utilizado libere íons de Si na solução, quanto naqueles em que o pó de Si é empregado e o ligante libere íons de $\mathrm{Al}$ na solução. Como é possível observar, estas combinações são precisamente representadas pelos concretos contendo pó de Al preparados com sílica coloidal (SC) e os concretos contendo pó de Si preparados com cimento (CAC), alumina hidratável (AH) ou alumina coloidal (AC).

Embora omecanismodepassivação sugerido semostreuma das possíveis explicações para a proteção dos pós metálicos em concreto, nenhum fundamento foi encontrado para esclarecer o comportamento do pó de Si no concreto preparado com CAC. Isto porque a solubilidade dos aluminosilicatos é consideravelmente baixa na faixa de $\mathrm{pH}$ entre 4 e $10[9,10]$. Entretanto, para valores de $\mathrm{pH}$ mais elevados, a velocidade de dissolução destes compostos aumenta drasticamente. Desta forma, considerando o valor de $\mathrm{pH}$ alcançado pelos concretos preparados com CAC (Tabela II), o recobrimento de aluminosilicato não seria capaz de suportar as condições alcalinas e o pó de Si deveria ser atacado. 
Com o intuito de avaliar a eficiência dos recobrimentos de aluminosilicato propostos e investigar se a resistência à corrosão poderia atuar utilizando-se um maior teor de antioxidante, novos testes foram realizados com concretos contendo 5,0\%-peso de pó metálico submetidos a um ajuste no valor de $\mathrm{pH}$ para condições alcalinas próximas àquelas desenvolvidas pelos concretos preparados com CAC.

Os resultados revelaram que mesmo quando uma grande quantidade de pó de $\mathrm{Si}$ foi adicionada aos concretos preparados com AH ou AC, nenhuma evidência da reação de corrosão foi observada (Fig. 4b). Entretanto, quando o pH destes concretos foi ajustado para valores próximos a 12,5, a corrosão do Si se mostrou evidente em ambos os sistemas. Estes resultados mostram que, nesta condição de $\mathrm{pH}$, o recobrimento de aluminosilicato é dissolvido deixando o metal desprotegido e vulnerável à corrosão. Por outro lado, os testes realizados com concretos preparados com CAC mostraram, novamente, uma grande estabilidade química do silício (Fig. 4b), o que sugere a formação de um recobrimento de aluminosilicato com superior resistência à corrosão neste sistema em particular. A diferença observada entre estes concretos pode estar relacionada à presença de íons $\mathrm{Ca}^{2+}$ oriundos da hidratação do cimento de aluminato de cálcio. Estes íons podem atuar como cátions intersticiais dentro da estrutura dos aluminosilicatos conferindo uma maior estabilidade química a este recobrimento [9]. Conseqüentemente, as partículas de $\mathrm{Si}$ apresentam uma maior resistência à corrosão, mesmo quando expostas às condições alcalinas agressivas dos concretos preparados com cimento. O mecanismo de passivação proposto ainda encontra suporte nos resultados obtidos com os concretos preparados com SC. Nestes sistemas, o aumento no teor de pó de Si fez com que a corrosão do metal ficasse mais evidente. Além disso, a elevação do pH do concreto foi responsável por intensificar a corrosão uma vez que a camada passivadora de $\mathrm{SiO}_{2}$ não resiste a condições altamente alcalinas [7].

Os testes realizados com os concretos preparados com SC e 5,0\%-p de pó de $\mathrm{Al}$ (Fig. 4a) mostraram que o mecanismo de passivação proposto também atua de maneira eficiente. Entretanto, quando o $\mathrm{pH}$ do concreto foi ajustado para condições criticas para o recobrimento de aluminosilicato, um expressivo aumento nos níveis de pressão foi observado, confirmando a corrosão do metal. Considerando o teste realizado com o concreto preparado sem ligante, a adição de um maior teor de pó metálico veio a confirmar a corrosão do alumínio, o que não se mostrava evidente no resultado discutido anteriormente (Fig. 3a).

Os resultados obtidos dão ênfase ao mecanismo de passivação proposto e viabilizam o emprego de pó de $\mathrm{Al}$ ou Si como antioxidante em concretos refratários contendo elevado teor de carbono. Os avanços obtidos neste trabalho devem contribuir para o continuo desenvolvimento de refratários de alto desempenho.
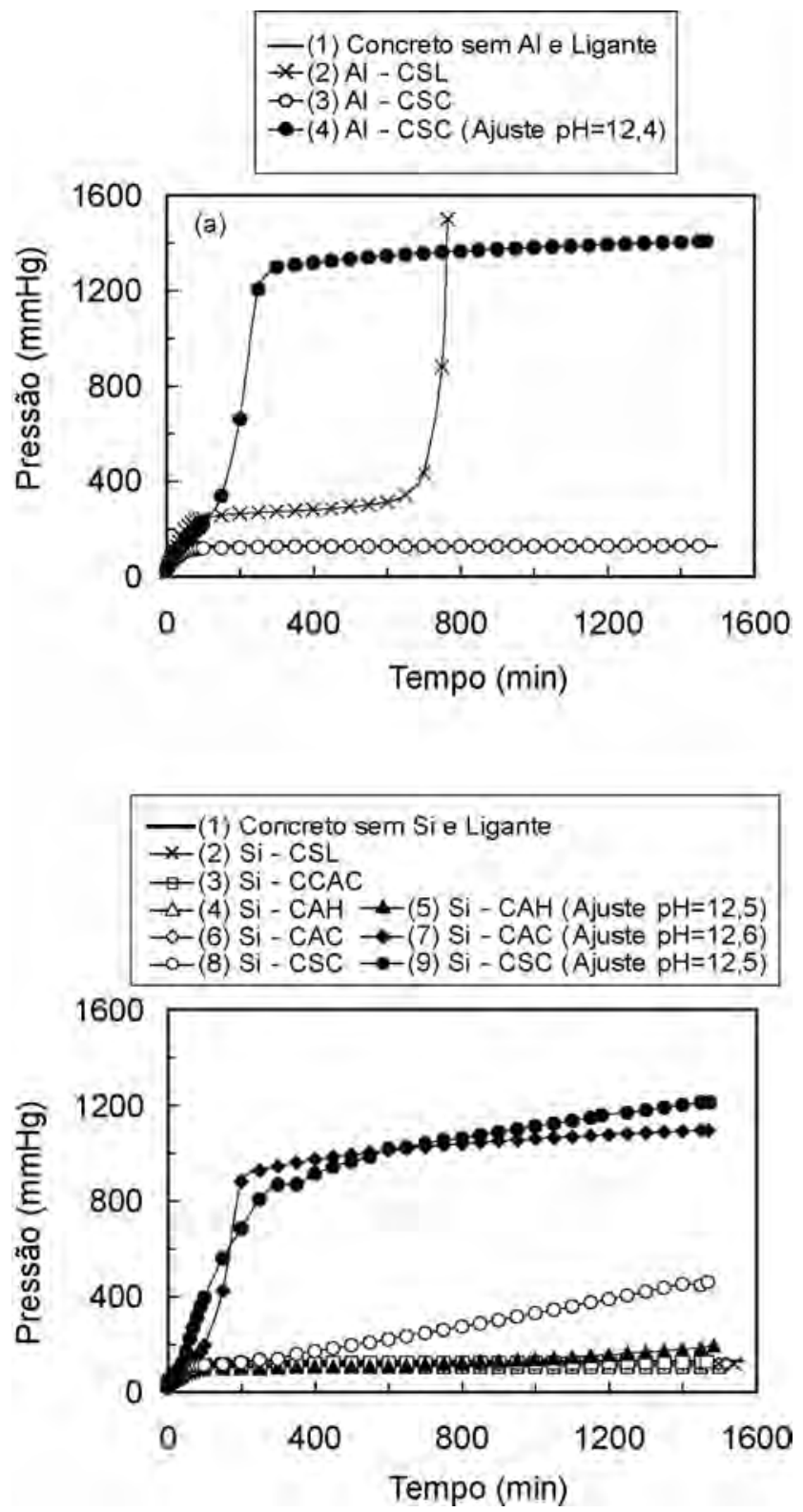

Figura 4: Testes de hidratação a $50{ }^{\circ} \mathrm{C}$ realizados com concretos refratários preparados com 5,0\%-peso de (a) pó de $\mathrm{Al}$ e (b) pó de Si utilizando diferentes ligantes e submetidos ou não a um ajuste de $\mathrm{pH}$ para condições alcalinas fazendo uso de uma solução de hidróxido de sódio $([\mathrm{NaOH}]=25,0 \mathrm{~mol} / \mathrm{L})$.

[Figure 4: Hydration tests $\left(50{ }^{\circ} \mathrm{C}\right)$ performed with refractory castables produced with 5.0 wt\% of (a) Al powder or (b) Si powder using different sort of binders and $\mathrm{pH}$ conditions. The $\mathrm{pH}$ adjustment to alkaline conditions was carried out using an aqueous sodium hydroxide solution $([\mathrm{NaOH}]=25.0 \mathrm{~mol} / \mathrm{L})$.

\section{CONCLUSÕES}

Os experimentos realizados com os pós de $\mathrm{Al}$ e $\mathrm{Si}$ mostraram que a resistência à corrosão destes metais é controlada, basicamente, pela estabilidade química da camada passivadora formada como resultado da reação entre 
o metal e a água. Os testes de hidratação realizados em água a diferentes temperaturas revelaram que o Si possui uma superior resistência à corrosão quando comparada ao Al. Além disso, as condições de $\mathrm{pH}$ do meio mostraram exercer uma grande influência sobre a corrosão do metal. Os testes realizados com concretos contendo $\mathrm{Al}$ ou $\mathrm{Si}$, preparados com os diferentes ligantes avaliados neste estudo revelaram que um novo mecanismo de passivação pode atuar sobre as partículas de Al e Si dentro de sistemas específicos. Neste mecanismo, o pó metálico é protegido por uma camada estável de aluminosilicato que proporciona uma elevada resistência à corrosão, possibilitando a aplicação tanto de Al como de Si como antioxidante em concretos refratários contendo elevado teor de carbono. Dentre as combinações testadas, o uso do cimento, alumina hidratável ou alumina coloidal se mostraram alternativas eficientes para a aplicação do pó de Si. No caso do pó de Al, apenas a sílica coloidal foi reconhecida como um ligante apropriado.

\section{AGRADECIMENTOS}

Os autores agradecem a FAPESP e ao CNPq pelo suporte oferecido e à Alcoa (Brasil), Unimetal (Brasil) e Elkem Refractories (Noruega) pelas amostras gentilmente cedidas.

\section{REFERÊNCIAS}

[1] S. Zhang W. E. Lee, Brit. Ceram. Trans. 101, 1 (2002) $1-8$.

[2] I. R. Oliveira, A. R. Studart, R. Salomão, V. C. Pandolfelli, Am. Ceram. Soc. Bull. 82, 10 (2003) 951-8.

[3] V. G. Domiciano, I. R. Oliveira, R. Salomão, V. C. Pandolfelli, Am. Ceram. Soc. Bull. 84, 5 (2005) 9101-5.

[4] M. D. M. Innocentini, L. A. Nascimento, A. E. M. Paiva, V. C. Pandolfelli, B. A. Menegazzo, L. R. M. Bittencourt, Am. Ceram. Soc. Bull. 82, 6 (2003) 45-51.

[5] S. Zhang, S. Hashimoto, W. E. Lee, Refrac. Applic. and News 8, 3 (2003) 21-5.

[6] T. Hara, N. Yasuda, K. Sugiyama, I. Shimizu, J. Techn. Assoc. Refract. Jap. 22, 2 (2002) 114-7.

[7] M. Pourbaix, Atlas of Electrochemical Equilibria in Aqueous Solutions, Pergamon Press, New York (1966).

[8] R. K. Hart, Trans. Faraday Soc. 53, 7 (1957) 1020-27.

[9] R. K. Iler, The Chemistry of Sílica, John Wiley \& Sons, USA (1979) p.3-104.

[10] D. L. Gallup, Geothermics 27, 4 (1998) 485-501.

[11] C. J. Gabelich, T. I. Yun, B. M. Coffey, W. R. Chen, I. H. Suffet, Proc. AWWA WQTC, Nashville, USA (2001)

(Rec. 18/07/2005, Ac. 12/09/2005) 